\title{
EL ASESINATO DEL GENERAL PRIM, SU BICENTENARIO Y LOS NEGOCIOS DE LA HISTORIA
}

\author{
DIEGO CARO CANCELA | UNIVERSIDAD DE CÁDIZ
}

ORCID iD: 0000-0002-4626-6555

\begin{abstract}
RESUMEN
Una de las polémicas más relevantes de la Historia Contemporánea de España ha sido la creada acerca de los autores y los inductores implicados en el atentado que le costó la vida al general Prim el 27 de diciembre de 1870, cuando era presidente del gobierno y ministro de la Guerra. Aunque la discusión ya venía de atrás, en la última década se ha exacerbado este interés con motivo dela conmemoración del bicentenario de su nacimiento en el año 2014 y la proximidad de los 150 años de su muerte. Pero en este debate no todo ha estado motivado por el siempre laudable propósito de aportar más luz a este todavía oscuro suceso. Algunos han visto también la oportunidad de "hacer caja" reescribiendo o adornando los viejos relatos ya conocidos o simplemente inventando nuevas y escandalosas hipótesis de nula o mínima base documental. Este trabajo pretende analizar lo publicado en forma de libros o artículos en revistas en las dos primeras décadas del presente siglo, especialmente al calor del citado bicentenario, y el estado actual del tema.
\end{abstract}

PALABRAS CLAVE

Prim, política, asesinato, responsables.

\section{THE ASSASSINATION OF GENERAL PRIM, ITS BICENTENARY AND THE BUSINESS OF HISTORY}

\begin{abstract}
One of the most relevant controversies in the contemporary history of Spain has been the one surrounding who were the authors and instigators involved in the attack that cost General Prim his life on 27 December 1870, when he was the prime minister and minister of war. Although the discussion was already relevant, in the last decade this interest has been stirred up by the commemoration of the bicentenary of his birth in 2014 and the proximity of the 150th anniversary of his death. But not everything concerning this debate has been motivated by the always laudable intention of bringing more light to this still dark event. Some have also seen the opportunity to "cash in" by rewriting or embellishing old stories already knew or simply making up new and scandalous hypotheses with no or minimal documentary basis. This work aims to analyze what has been published in the first two decades of this century in the form of books or journal articles, especially in the heat of the aforementioned bicentenary, and what the current state of the subject has been.
\end{abstract}

\section{KEYWORDS}

Prim, politics, murder, responsible. 


\section{EL ESPADÓN MÁS POPULAR DEL SIGLO}

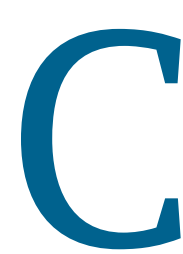

uando en el año 2014 Carlos Dardé publicaba una breve biografía del general Prim en una conocida revista de divulgación histórica, no dudaba en presentarlo como "el espadón de las mil caras". Y no le faltaba razón, porque siendo Prim el militar más popular de todos los que ocuparon la vida política española en las décadas centrales del siglo XIX, ninguno tuvo una personalidad tan compleja y contradictoria. De voluble militancia política, que le llevó del progresismo al acercamiento a la Unión Liberal en un viaje de ida y vuelta, fue al mismo tiempo el implacable impulsor del racista Código Negro durante su breve etapa de capitán general de Puerto Rico y el promotor principal de la Constitución de 1869, la más democrática que tuvo la España del siglo XIX. Durante toda su trayectoria como diputado y senador estuvo al servicio de los intereses económicos de la burguesía industrial catalana y su programa radicalmente proteccionista, pero también formó parte del gobierno que impulsó la legislación librecambista más notable de la centuria. Como militar, demostró su extraordinario valor en la Primera Guerra Carlista y la guerra de África de 1860, pero también fue un fracasado conspirador contra la monarquía isabelina hasta que los unionistas no se sumaron al pacto de Ostende, facilitando el éxito de la Gloriosa, a mediados de septiembre de 1868. Sin embargo, si su notable popularidad se asentó especialmente durante su actuación en la guerra africana, en batallas como la de los Castillejos o Wad-Ras contra los entonces llamados "moros", el interés historiográfico por su vida ha venido especialmente impulsado por las notables incógnitas que todavía hoy rodean al atentado que provocó su muerte, lo que ha propiciado todo tipo de publicaciones, hechas en ocasiones por autores que desconocen por completo las normas más elementales del método de investigación histórica ${ }^{1}$.

\section{LOS ASESINOS DEL GENERAL PRIM. LA HISTORIA “OFICIAL”}

En 1960 Antonio Pedrol Rius, reusense como Prim y entonces un abogado experto en derecho mercantil, publicaba la primera edición de un libro que, pese a sus debilidades, mar-

1 Son más de una decena las biografías que se han escrito sobre el general Prim desde su muerte hasta nuestros días, sin tener en cuenta los libros que sólo se han preocupado del atentado que le costó la vida. Quizá las más conocidas sean las siguientes ordenadas cronológicamente: ORELLANA, Francisco José. Historia del general Prim, Barcelona, La Ilustración, 1872; SANTOVENIA, Emeterio, S. Prim, el caudillo estadista, Madrid, Espasa, 1933; OLIVAR BERTRAND, Rafael. El caballero Prim, Barcelona, Luis Miracle Editor, 1952, 2 vols.; POCH NOGUER, José. Prim, Barcelona, Editorial Juventud, 1965; ANGUERA, Pere. El general Prim: biografía de un conspirador, Barcelona, Edhasa, 2003; DIEGO GARCÍA, Emilio de. Prim. La forja de una espada, Barcelona, Planeta, 2003; RUBIO, María José (coord.). Juan Prim $\gamma$ Prats. Discursos parlamentarios, Madrid, Congreso de los Diputados, 2012; DIEGO GARCÍA, Emilio de. Prim. Mucho más que una espada, Madrid, Actas, 2014; DONÉZAR, Javier. Prim: un destino manifiesto, Madrid, Sílex, 2016; RUBIO, Javier. Juan Prim. Sus años de gobernante. Su asesinato. Una revisión necesaria, Madrid, Ministerio de Asuntos Exteriores, 2017. 
caría de forma indeleble toda la historiografía que posteriormente se escribiría sobre el magnicidio. Desde entonces, Los asesinos del general Prim ha tenido varias reediciones y pese a que algunos de sus planteamientos son más que discutibles, se ha convertido en una obra de referencia presente en todas las biografías que se han escrito sobre este militar y político. Podríamos decir que su relato del atentado se ha convertido en la versión "oficial" o "canónica" del mismo porque se sustentaba en la consulta del imponente sumario judicial que provocó el suceso - entonces decía que tenía más de 18.000 folios- que durante décadas había estado arrumbado en el edificio de un juzgado de Madrid, sin que nadie se hubiera acordado de él.

Este abogado mercantilista analizó el sumario y, como es conocido, estableció la siguiente conclusión sobre lo sucedido: consideraba como principal responsable del atentado contra Prim al republicano jerezano José Paul y Angulo, entonces diputado en las Cortes Constituyentes, al que calificaba directamente de "señorito revolucionario (...) asesino y jefe de asesinos", situándolo en el lugar de los hechos al frente de los individuos que actuaron en la noche del 27 de diciembre en la calle del Turco ${ }^{2}$. ¿El motivo? José Paul, que había colaborado estrechamente con Prim en los preparativos de la "Gloriosa", se sintió engañado por éste cuando decidió apostar por la monarquía como forma del Estado en la Constitución de 1869. Desde entonces, y especialmente a lo largo de 1870, desde las páginas de un periódico, El Combate, que se decía que era de su propiedad, se lanzaron múltiples ataques a la figura del militar, algunos rozando la amenaza. Esta circunstancia, junto al presunto reconocimiento de su voz entre los atacantes de la berlina en la que iba el general, se convirtieron en las principales pruebas de cargo que se formularon contra él y que terminaron en una orden de detención dictada por el juzgado, cuando ya se había escondido y dado a la fuga.

Sin embargo, Paul no estuvo solo en la preparación del magnicidio, ni en el reclutamiento de sus presuntos colaboradores. Según los testimonios recabados a diferentes testigos e inculpados en los hechos, había contado con dos cómplices privilegiados. José María Pastor, el entonces jefe de la escolta de seguridad del general Serrano, el regente del Reino, y Felipe Solís y Campuzano, coronel del ejército y ayudante militar del duque de Montpensier, cuñado de la derrocada Isabel II y aspirante al trono de España con el respaldo de una parte de la dirigencia de la Unión Liberal.

2 PEDROL RIUS, Antonio. Los asesinos del general Prim, Madrid, Civitas, 1990, cuarta edición, p. 65. 


\section{DIEGO CARO CANCELA}

Llama la atención que quien acusaba con tanta facilidad a Paul de asesino y organizador del crimen no encontrara ninguna responsabilidad en los dos principales personajes a los que Pastor y Solís estaban subordinados, esto es, Serrano y Montpensier respectivamente, pese a las pruebas que se presentaron en la instrucción del sumario contra ellos, que terminaron provocando la detención y el encarcelamiento temporal de ambos. Dice Pedrol sobre Pastor que era "hombre de confianza, de mucha confianza, tanto del general Serrano, como de su ayudante el marqués de Ahumada" y que incluso "gozaba de la protección de Sagas$\mathrm{ta}^{\prime \prime}$. Pero, sorprendentemente, según escribe el abogado reusense, "el hecho de que Pastor estuviera al inmediato servicio del general Serrano no nos certifica ni mucho menos que estuviera trabajando en favor de su jefe", afirmando a continuación, de su propia cosecha y sin más pruebas que, "Pastor no es el fanático de ninguna idea ni el seguidor incondicional de ningún personaje" ${ }^{4}$. Y la misma exculpación lanza sobre la figura del duque de Montpensier, pese a la implicación y la detención de su ayudante por la participación en los hechos y en otro atentando anterior frustrado contra Prim y que llevaría a un fiscal a pedir el procesamiento del propio duque. Para Pedrol, el que el aristócrata de origen francés reaccionara a favor de Solís, "no presupone que conociese por anticipado lo que éste tramaba" 5 .

Pues bien, aunque estas no son las únicas afirmaciones algo temerarias del abogado reusense, sus tesis han tenido un largo recorrido historiográfico y han sido reproducidas sin ninguna comprobación posterior en los años siguientes por otros autores que han intentado reconstruir la trayectoria vital del entonces presidente del Gobierno y ministro de la Guerra. Esto es lo que, por ejemplo, hacía años después el diplomático Javier Rubio en la completa monografía que publicaba en 1989 sobre España y la política internacional en el contexto de la guerra franco-prusiana de $1870^{6}$. Rubio también volvía sobre el atentado, consultando el sumario, pero sus conclusiones variaban poco de las establecidas por Pedrol: Paul fue el "destacado coautor del asesinato", siendo Montpensier su principal inductor, porque Prim fue quien había impedido que se convirtiera en rey de España después de la caída de Isabel II, mientras que exculpaba completamente al general Serrano, pese a que reconocía que los testimonios que había sobre Pastor en el sumario eran "abrumadores"”

\footnotetext{
3 Ibídem., p. 83.

4 Ibídem., p. 92

5 Ibídem., p. 119.

6 RUBIO, Javier. España y la guerra de 1870, Madrid, Ministerio de Asuntos Exteriores, 1989, tres volúmenes.

7 Ibídem., vol. I, pp. 279-281. Las razones que da para la exoneración de Serrano en la página 282.
} 


\section{3. ¿POR QUÉ ASESINARON A PRIM? UNAS TESIS MÁS QUE DISCUTIBLES}

En este panorama tendremos que esperar al último año del siglo XX para conocer la siguiente aportación que se presenta como fundamental para desentrañar todos los misterios del magnicidio. El título del libro que firmaba José Andrés Rueda no podía ser más expresivo y atractivo, comercialmente hablando: ¿Por qué asesinaron a Prim? La verdad encontrada en los archivos ${ }^{8}$.

José Andrés Rueda, que era presentado por el prologuista de su trabajo como "un aficionado a la Historia que ha operado como un profesional", nos decía más adelante que lo que presentaba era el resultado de "cinco años de investigación", tras leer los más de dieciséis mil folios que formaban el sumario y que no habían sido expoliados ${ }^{9}$. No dudaba en denunciar la manipulación que Pedrol había hecho en su libro del texto de la autopsia del muerto que en su día firmó el doctor Fuente Chaos y a continuación en una nota a pie de página se hacía tres preguntas sobre la obra del abogado reusense que no iban a tener contestación porque este había fallecido:

“¿Cuántas cosas del libro de Pedrol fueron amañadas para dar fidelidad al texto $\gamma$ poder narrar una historia creíble?, ¿Por qué Pedrol no cita en ningún momento de dónde salieron sus datos?, ¿Qué pensaba, que a su libro jamás se le opondría nuevos textos, sacando a la luz algunos de los artificios por él usados?"10.

Sin embargo, y a pesar que el trabajo de José Andrés Rueda sí incluye lo que no tenía el libro de Pedrol, notas a pie de página en las que menciona correctamente de donde proceden las citas literales que aparecen en el cuerpo de la investigación con claras referencias a las páginas del propio sumario, la organización interna del libro presenta también importantes problemas que dificultan notablemente la comprensión final del relato que se ofrece y de las incógnitas que se pretenden desvelar. En primer lugar, el libro contiene copias de documentos y trata cuestiones que nada tienen que ver con el objetivo final del mismo, como era poner al descubierto la causa del asesinato de Prim. Por ejemplo, en el primer capítulo, en el que hace una aproximación biográfica a su figura, incluye una carta que escribe al almirante francés que compartía su expedición a Méjico en el año 1862, que ocupa nada menos que seis páginas del texto y que nada tiene que ver con el tema que se quiere aclarar ${ }^{11}$. En cam-

\footnotetext{
8 El libro lo editaba EUNSA, que era la editorial de la Universidad privada de Navarra, vinculada al Opus Dei.

9 RUEDA VICENT, José Andrés. op. cit., p. 29.

10 Ibídem., p. 97.

11 Ocupa las páginas 56-61.
} 


\section{DIEGO CARO CANCELA}

bio, los seis años en los que Prim se coloca al frente del Partido Progresista y lidera distintas conspiraciones hasta llegar a la "septembrina" se liquidan con dos frases: "Desde 1862 hasta 1868, la vida del general está dedicada a la política. Si bien no es uno de los mejores oradores del momento, sí levanta enconadas reacciones" ${ }^{12}$.

Más sorprendente nos parece lo que hace en la nota biográfica del duque de Montpensier. De las 33 páginas que le dedica, 22, es decir, el 67 por ciento, están volcadas en narrar el duelo que mantuvo con el infante Enrique de Borbón, reproduciendo comunicaciones, acta de una reunión o testimonios personales que en la mayoría de los casos son auténticamente irrelevantes. Estas 22 páginas ocupan a su vez el 10 por ciento del total del texto del libro excluidos los anexos y apéndices ${ }^{13}$. Y lo mismo ocurre con las casi veinte páginas que ocupan la vida de José Paúl. Un irrelevante lance amoroso de este personaje en el Jerez de la Frontera de 1867, y el cruce de cartas que provoca, llena las cuatro primeras páginas de esta breve biografía y dos páginas y media le dedica a un asunto marginal para lo que se quiere "descubrir", como fue al duelo que mantuvo con Felipe Ducazcal, el entonces "jefe" de la llamada "Partida de la Porra" 14 .

Pero estas cuestiones no son las que más llaman la atención. Lo que resulta verdaderamente sorprendente son las tres tesis que se plantean en el libro y que aparentemente constituyen esa "verdad encontrada en los archivos" que se cita en el subtítulo del mismo. En primer lugar, lo que cuenta en el capítulo que titula “¿Quién podía desear la muerte de Juan Prim?" ${ }^{15}$.Junto a los enemigos ya conocidos, como alfonsinos, montpensieristas, republicanos o unionistas como el general Serrano, José Vicente Rueda también mete a la Masonería, a pesar de la pertenencia del general a una logia madrileña. ¿Y cómo lo argumenta? Diciendo que la Masonería quería gobernar "con un código católico extremo" (sic), que no quería "una revolución lenta" (sic) y que deseaba su muerte "por una supuesta traición a sus ideales" (sic), que no se citan ${ }^{16}$.

En segundo lugar, en este libro se sostiene una teoría extravagante, que años después volvería a tener vigencia y que desmienten todas las fuentes documentales de la época, ya sean periodísticas o archivísticas, y las memorias que dejaron escritas algunos de los testigos que vivieron en primera línea los acontecimientos. Rueda escribe que "es muy posible que el ge-

12 Ibídem., p. 61.

13 La aproximación biográfica al duque ocupa las páginas 155-186 y el duelo y todos sus pormenores se cuentan en las páginas 156-178.

14 El lance amoroso en las páginas 187-190 y el duelo en las páginas 195-197.

15 Ibídem., pp. 105-114.

16 Ibídem., p. 109. 
neral estuviese muerto desde el mismo día 27, ya que de encontrarse aún con vida hubiesen permitido que el juez le tomase declaración" ${ }^{17}$. Por tanto, la fecha que hasta ahora se había dado de su fallecimiento, el 30 de diciembre era una falsedad.

Finalmente, también resulta llamativo lo que escribe sobre quiénes fueron los responsables del magnicidio. Pese a las críticas que hace a la tesis de Pedrol, su conclusión es la misma, salvo que es más explícito en el reparto de los papeles que asigna y que da más protagonismo a Serrano y Montpensier. Escribe en la principal tesis del libro: "el ejecutor fue José Paúl y Angulo, el encubridor Pastor y el instigador Solís y Campuzano" ${ }^{18}$.

Y sobre la responsabilidad de la Masonería, escribe lo siguiente, que no necesita más comentarios:

"Creemos que su implicación es cierta, aunque tras hablar con algunos masones de la actualidad, todos niegan con rotundidad que interviniera en el atentado. Este investigador está dispuesto a rectificar en este punto si los propios masones permitiesen el acceso a esos documentos... en caso de existir" ${ }^{\prime 1}$.

Pues bien, pese a hipótesis tan cuestionables por su discutible rigor histórico, estos dos libros de Pedrol y Rueda son las fuentes principales en las que se han sostenido los relatos biográficos que se han escrito sobre el atentado que le costó la vida a Prim. Así ocurrió, por ejemplo, con la monografía que en el año 2003 publicó Pere Anguera, una de las más completas hasta el día de hoy ${ }^{20}$. Y estas mismas fuentes se repiten en la otra biografía aparecida ese mismo año escrita por Emilio de Diego, según las referencias que cita en las notas a pie de página ${ }^{21}$.

\section{LA“COMISIÓN PRIM" DE LA UNIVERSIDAD CAMILO JOSÉ CELA.CON ELLA LLEGÓ EL ESCÁNDALO}

Como era de esperar, tratándose de un personaje históricamente tan interesante como Prim, la proximidad de la fecha del bicentenario de su nacimiento en el año 2014 propició la aparición de distintas iniciativas, dentro y fuera del ámbito universitario, presentadas

\footnotetext{
17 Ibídem., p. 234.

18 Ibídem., p. 230.

19 Ibídem., p. 231. Desconocemos el rigor histórico que pueden tener las opiniones personales de los masones del año 2000 sobre el asesinato de Prim ocurrido 130 años antes.

20 ANGUERA, Pere. op. cit., especialmente las pp. 622-630.

21 DIEGO GARCÍA, Emilio de. Prim. La forja de una espada, Barcelona, Planeta, 2003, especialmente las pp. 371-377.
} 


\section{DIEGO CARO CANCELA}

con el objetivo de proporcionar un mejor conocimiento del tiempo histórico que le tocó vivir, o de alumbrar aquellos aspectos oscuros que rodearon al atentado que le costó la vida o la causa definitiva que le provocó la muerte. Pues bien, aunque la que podría considerarse como comisión "oficial" para la celebración de este bicentenario - la llamada Sociedad Bicentenario General Prim 2014- fue creada a principios del año 2010, antes de que se conocieran las primeras iniciativas públicas de ésta, dos años después, dentro de la Universidad Camilo José Cela de Madrid (UCJC) surgió otra comisión, la titulada Comisión Universitaria Prim de Investigación, presidida por Francisco Pérez Abellán, un conocido periodista de sucesos, que se presentaba como "director del Departamento de Criminología" de esta univer$\operatorname{sidad}^{22}$. Esta última comisión se planteaba como primer objetivo conocer a los auténticos asesinos que participaron en el atentado de la calle del Turco y, como segundo, cuál fue la verdadera causa de la muerte del general a través del análisis forense de sus restos.

Pues bien, pese a que el presidente de la misma definía a su comisión como una "institución voluntaria, altruista y multidisciplinar, sin ánimo de lucro", pronto se vería que eran otros los objetivos que se pretendían, entre los que no faltaban la búsqueda de una notoriedad pública para atraer la atención de los medios de comunicación, que diera, además, una propaganda gratuita y fácil a los libros que se iban a publicar a continuación o a las conferencias o charlas para las que se ofrecía el citado Pérez Abellán a todo tipo de instituciones a través de su propia página web. De este modo, el escándalo no tardaría en llegar ${ }^{23}$.

La primera actividad que conocemos que realizó esta Comisión de Investigación Prim fue la exposición pública de distintos tomos del sumario generado por el atentado en las propias instalaciones de la Universidad Camilo José Cela. La misma, se anunciaba que era la "gran exposición del sumario de Prim" en el hall del Aulario y que estaría abierta desde el 12 de junio hasta el 11 de julio del 2012. Y, en la noticia de prensa que se daba a través del diario Libertad Digital, del que era su habitual colaborador, Francisco Pérez Abellán, se informaba ya que los investigadores de esta comisión habían hallado la lista de los “asesinos materia-

22 Se anunció su constitución el 12 de enero de 2012. Vid. Periodista digital (16-1-2012).

23 La definición de los objetivos de la comisión en Libertad Digital (12 de enero de 2013) (consulta realizada el 5 de noviembre de 2020). Tenemos que señalar que en los días que escribimos este trabajo-principios de diciembre del año 2020-hemos consultado detalladamente la página web de la Universidad Camilo José Cela y no hemos encontrado ninguna referencia ni a la existencia de un Departamento de Criminología -si hay una titulación con este nombre-, ni de esta llamada Comisión Universitaria Prim de Investigación, ni a los posibles resultados de sus trabajos. Por tanto, toda la reconstrucción que hacemos de las actividades de esta comisión se ha basado en las noticias de prensa que hemos podido recuperar a través de periódicos que están digitalizados en Internet y que son de consulta abierta y de la lectura de los artículos en revistas o de los libros que han ido publicado sus miembros más conocidos. 
les" de Prim y "las mayores acusaciones contra el duque de Montpensier y el general Serrano, imputados como presuntos autores intelectuales del crimen"24.

Lanzados por esta pendiente, el siguiente paso que dio esta comisión fue ponerse en contacto con el Ayuntamiento de Reus para obtener la autorización necesaria que le permitiera hacer un estudio anatómico-forense de la momia de Prim. Con esta finalidad, a mediados de junio de 2012, el secretario de esta Comisión Prim de Investigación se trasladaba a Reus con cuatro "especialistas" más y se reunía con profesionales del hospital San Joan de la ciudad y de la Universidad Rovira i Virgili, con el objetivo de ampliar el equipo y completar el "exhaustivo estudio" que -según decía- estaba realizando ${ }^{25}$. Según este secretario, lo que la comisión pretendía hacer era "escribir una nueva página de la historia" porque iba a desvelar "por completo quién mató a Prim y por quén 26 . Sin embargo, el análisis del cuerpo del estadista catalán que gobernó España no pudo hacerse hasta después del verano, a finales de septiembre de 2012 con un nuevo forense incorporado a la comisión que también se desplazó a Reus ${ }^{27}$. Y, aunque se advirtió a la prensa que las conclusiones de la autopsia se sabrían en un plazo de veinte días y seis meses, ya uno de los investigadores admitía en privado, pero convenientemente filtrado a la prensa, que el general “murió en el acto, no puede haber dudas" 28 .

No se tardaría tanto, porque apenas habían pasado dos meses a finales de septiembre, y ya Francisco Pérez Abellán daba a conocer a la opinión pública un adelanto provisional de las conclusiones del informe forense que se había realizado, y una de ellas no podía ser más espectacular, según se publicaba. Prim no había muerto de una septicemia generalizada como se había creído hasta entonces, sino que los forenses habían descubierto unas "profundas marcas en el cuello y la nuca de la momia", que "examinadas debidamente y en consonancia con la bibliografía científica consultada" eran compatibles con una muerte

24 A continuación, harían una publicación comentada en la Red de los 78 tomos y los cuatro volúmenes que formaban el conjunto del sumario, describiendo el contenido de cada uno, encabezándola con los siguientes titulares: "Novedad mundial. Índice general del sumario por el asesinato del general Prim para moverse en una causa de miles de folios cambiados de lugar. Realizado por la "Comisión Prim" del Departamento de Criminología de la Universidad Camilo José Cela y cedido a la comunidad científica internacional. Última edición con las marcas de los grandes descubrimientos". Se ha podido consultar en: http://www.maalla.es/Doc/Asesinato\%20Prim.pdf (consulta realizada el 6-5-2020).

25 La Vanguardia (21-6-2012). Edición digital.

26 Ibídem. Los tres forenses eran María del Mar Robledo, José Antonio Lorente y Delfín Villalaín. Robledo está especializada en antropología forense e investigación criminal y dirigía el laboratorio de Criminalística de la Universidad Complutense de Madrid. Además del Caso Prim, también trabajaba, entre otras cosas, en la identificación de fosas comunes de la etapa de Sendero Luminoso en Perú. José Antonio Lorente dirigía el Laboratorio de Medicina Legal de la Universidad de Granada, además de ser conocido por su investigación sobre los restos de Colón. Y el tercero de los forenses que había viajado a Reus en este primer viaje preparatorio había sido Delfín Villalaín, catedrático de Medicina Legal y profesor del Departamento de Criminología de la UCJC, autor de miles de autopsias y mediáticamente conocido por el caso de las niñas de Alcásser.

27 El Periódico (30-9-2012), edición digital.

28 Ibídem. 
por estrangulación a lazo perpetrada con una banda de cuero o cinturón, cuando estaba postrado en su cama después del atentado ${ }^{29}$. Y el titular con el que el periódico daba esta información tampoco podía ser más contundente: “Un sicario estranguló a Prim”.

Lo que no se contaba en esta información era algo que se sabría posteriormente: tres de los cuatro forenses que se habían comprometido a participar en el examen de los restos de Prim rechazaron compartir esta "revolucionaria" conclusión por lo que el informe final solamente fue firmado por la doctora María del Mar Robledo ${ }^{30}$.

Probablemente esta circunstancia retrasó la preparación de las conclusiones finales de esta Comisión Prim de Investigación porque hubo que esperar hasta el 11 de febrero de 2013 para que el mismo se difundiera en varias páginas con el membrete de la UCJC y de su Departamento de Criminología firmado por Pérez Abellán ${ }^{31}$. Aunque en estas conclusiones la redacción del texto con el que sostiene el estrangulamiento de Prim ya no es tan contundente, la investigación se convirtió en noticia en los principales diarios y en todos los titulares con los que se presentaba se afirmaba categóricamente que Prim murió estrangulado ${ }^{32}$.

Ante el escándalo periodístico que se formó, la llamada Sociedad Bicentenario General Prim 2014, que hasta entonces apenas si había tenido presencia pública porque se había limitado a colocar una placa en la calle de Madrid donde se produjo el atentado, se vio obligada a reaccionar y le encargó a un equipo médico-forense de la Universidad Complutense de Ma-

29 https:/www.larazon.es/opinion/columnistas/un-sicario-estrangulo-a-prim-CH191026/ (consulta realizada el 24-112020).

30 Pérez Abellán explicaba meses después, de la siguiente manera, las "deserciones" de estos tres forenses: "Villalaín prácticamente desistió por complicaciones familiares, pasó semanas sin cogerme el teléfono, aunque yo soy el director del departamento en el que da clases. No pude tratar nada con él. El profesor Aitor Curiel, atención a éste, no quiso presentar su informe de conclusiones porque dijo que necesitaba una investigación más larga. Lo que al final dijo también el doctor Villalaín, afirmando vagamente que sería de varios meses y con pruebas complicadas y de alto coste. Algo que se escapaba a nuestros propósitos, por lo que seguimos adelante sin ellos... El doctor Lorente, de Granada, por motivos que desconozco, no se llevó cabellos de Prim del quirófano para sacar el ADN y tuvimos que mandárselos después, pero todavía no ha aportado a día de hoy la prueba de ADN". Que quedara como única forense disponible la doctora Robledo al director de la comisión le importaba poco porque como decía a continuación, con un único forense se habían hecho las autopsias de Kennedy o Marilyn Moroe. Fuente: Libertad Digital (18-2-2013). Consulta realizada el 13-12-2013.

31 Como ya se ha señalado, en la página web de la UCJC no hay ningún rastro de esta Comisión Prim o de sus informes, a pesar de que la prensa anunció que el 13 de febrero de 2013 se iban a publicar en la página web de esta universidad las conclusiones de esta comisión de investigación Se pueden encontrar estas conclusiones finales de la comisión con el membrete oficial de la institución en la siguiente dirección: https://www.yumpu.com/es/document/view/14894128/ conclusiones-universidad-camilo-jose-cela (consulta realizada el 3-12-2020).

32 El texto aparecía en la sexta conclusión "médico-forense" y quedaba redactado de la siguiente manera: "Los surcos observados en el cuello "compatibles con una posible estrangulación a lazo" encajan así en una necesidad de los asesinos de Prim de no permitir la recuperación del mismo". El subrayado y la negrita es nuestra. El encabezamiento con el que el diario El Mundo daba la información el 11 de febrero de 2013 era el siguiente: "El general Prim fue estrangulado". Posteriormente, la doctora Robledo publicaría su informe en forma de libro y un resumen del mismo en un artículo titulado Estudio médico legal del general Prim en IUS. Revista del Instituto de Ciencias Jurídicas de Puebla, México, número 34 (2014), Pp. 198-218. El libro está disponible en: https://www.amazon.es/Las-muertes-Prim-Mar\%C3\%ADa-Robledo-ebook/dp/B07GYDCVQX (consulta realizada el 24-11-2020). 
drid un segundo análisis de la momia de Prim. Sus conclusiones eran presentadas el 18 de diciembre del 2013, en este caso firmadas por los seis médicos que participaron en el mismo, y rechazaban completamente la tesis del estrangulamiento que defendía la doctora Robledo de la comisión de la UCJC. Según se decía en la quinta y última de las conclusiones del informe: "la naturaleza de las heridas sufridas, y los tratamientos disponibles en la época, justifican la muerte por una complicación infecciosa a los tres días del atentado, evolución clínica por otra parte reflejada en numerosos testimonios" ${ }^{33}$.

Lo que vino a continuación fue un doble enfrentamiento. Por un lado, Pérez Abellán, que a través de la tribuna que tenía en el diario Libertad Digital se dedicó a descalificar este informe de la UCM y a los miembros que formaban la Sociedad Bicentenario, mientras que la doctora Robledo, por su cuenta, también emprendió su propia campaña de denuncias contra los que hasta entonces habían sido sus compañeros en la Escuela de Medicina Legal de la UCM, acusándolos de distintas irregularidades que tuvieron un relativo eco periodístico y que -por lo que parece- terminaron con su salida final de esta institución universitaria ${ }^{34}$.

Pues bien, pese a la rotundidad con la que el informe de la UCM rechazaba la tesis del estrangulamiento, Francisco Pérez Abellán, decidía mantener el de su comisión y emprendía

33 El llamado "Informe sobre el estudio médico-legal de la momia del general Prim" se encuentra todavía disponible en la página web de la Universidad Complutense de Madrid. Este informe descarta la tesis del estrangulamiento de Prim. argumentando que los pliegues que presentaba en el cuello y otras partes del cuerpo estaban producidos por la presión ejercida por la vestimenta de su mortaja. Así se explicaba: “Dichos surcos se producen a consecuencia de la inflamación postmortem del cuello, derivada del embalsamamiento, en el que los tejidos blandos hinchados se comprimen contra la ropa (cuello y corbatín superpuesto). Estos pliegues por ropa son frecuentes en los cuerpos momificados, y también a veces aparecen en los cadáveres putrefactos por la misma dilatación enfisematosa" (p. 12). Y más adelante, decía: "Por otra parte, los surcos cervicales que observamos precisan para su formación un mantenimiento muy prolongado de la presión, es decir, la permanencia del lazo, sea cual sea su naturaleza, alrededor del cuello, circunstancia que se evitaría en un caso criminal que quisiera disimularse, pero algo lógico cuando se forma por las ropas en el cadáver. Tampoco aparece ningún signo violento en el cuello en el estudio del TAC realizado. Así lo especifica el informe del especialista radiólogo: "No hay signos radiológicos de aplastamiento de las estructuras glóticas. Son visibles la epiglotis, pliegues gloso-epiglóticos y ariteno epiglóticos, con morfología y simetría normales" (p. 16). Fuente: www.ucm.es (consulta realizada el 8-5-2020). Este mismo equipo ha publicado estas mismas conclusiones en: DORADO FERNÁNDEZ, E. y otros. La muerte del general Prim. Estudio histórico y médico legal en Revista Internacional de Antropología y Odontología Forense, vol. 3, nº 1 (2020), pp. 31-54.

34 Este enfrentamiento o mejor dicho las críticas de Pérez Abellán contra los miembros de la Sociedad Bicentenario y todas sus repercusiones mediáticas se comentan con detalle en: CAMENO MAYO, Diego. El bicentenario del general Prim y la polémica sobre su asesinato en los medios de comunicación españoles, en Revista Internacional de Historia de la Comunicación, $\mathrm{n}^{0} 13$ (2019), pp. 107-128. Las denuncias de la doctora Robledo en $A B C$ (6 de mayo de 2014), con el siguiente titular: "Imputada la cúpula de la Escuela de Medicina Legal de la Complutense. Su director y tres forenses más deberán aclarar si falsificaron la firma de una prestigiosa colega". Y en El Mundo del 30 de septiembre de 2014: Clases "falsas" por dinero público e influencia en la Complutense Una profesora de Medicina denuncia que le hacen firmar cientos de horas falsas. Así se infla el departamento de docentes asociados y se consiguen más fondos". Fuente: https://www.elmundo.es/ madrid/2014/09/30/542b13a8268e3ebc398b4571.html (consulta realizada el 4-2-2020). Cuando se escribe este artículo -en el mes de diciembre del año 2020- la doctora María del Mar Robledo Acinas aparece como directora general de un llamado Instituto Europeo de Investigación Criminal (IEIC) "una institución privada que opera a nivel internacional", al frente de "un gran proyecto docente" en el ámbito de la Criminología, ofreciendo también sus servicios jurídicos "en asuntos penales, civiles, mercantiles y de cualquier otra jurisdicción". Aunque en su página de inicio aparece una dirección postal en Londres, en la pestaña de "¿Quiénes somos?" dice que su dirección general se encuentra en la ciudad de Madrid, "en el corazón del barrio de Salamanca". Vid.: https://ieicriminal.ddns.net/index.php/home/bienvenida (consulta realizada el 4-12-2020). 
una huida hacia adelante, defendiéndola "contra viento y marea" a través de dos libros que publicaba a continuación, a lo largo del año 2014. En el primero, que se titulaba Prim, la momia profanada, decía que quería dar testimonio del "vía crucis" que había tenido que vivir para "esclarecer, casi siglo y medio después, las circunstancias de la muerte del general Juan Prim, un asesinato por estrangulamiento en el que participó la masonería" ${ }^{35}$. Y el segundo era Matar a Prim, que se presentaba diciendo en la portada que "Por fin se resuelve el asesinato que cambió la historia de España". Un relato en el que se mezclaba la biografía de Prim, las críticas a la Sociedad Bicentenario 2014, la narración de los trabajos de la comisión de la UCJC que había presidido, su tesis del estrangulamiento, pero también la de la culpabilidad de Serrano, primero porque su jefe de escolta había tenido un papel importante en la preparación del atentado y, en segundo lugar, porque el propio Serrano debió tener un papel decisivo en el momento del estrangulamiento por su cercanía personal al herido en su cama, como se defendía explícitamente en los capítulos VII y VIII, titulados respectivamente "Lo remataron con estrangulación a lazo" y “Asesinado bajo la protección de Serrano" ${ }^{36}$.

En esta tesitura, Pérez Abellán, además, a través de su página web personal se ofrecía como presidente de la comisión para "dar conferencias en instituciones, Ayuntamientos, Diputaciones, Colegios, Universidades y Asociaciones culturales, recreativas, profesionales, deportivas y criminológicas a fin de divulgar la apasionante investigación del misterio criminal del asesinato del general Juan Prim y Prats", un ofrecimiento que terminaba con la siguiente exclamación: “ESTA VEZ LOS ASESINOS NO ESCAPARÁN!"37.

35 PÉREZ ABELLÁN, Francisco. Prim. La momia profana, Madrid, Poe Books, 2014.

36 PÉREZ ABELLÁN, Francisco. Matar a Prim, Barcelona, Planeta, 2014. Los capítulos VII y VIII ocupan las páginas 115-145. El libro incluía, además, dos apéndices. En el primero se decía que era la "Parte principal del sumario 306/1870" y en el segundo se recogían todas las conclusiones finales de la Comisión Prim de Investigación.

37 Fuente: perezabellan.webcindario.com (consulta realizada el 24 de noviembre de 2020). Cuatro años después, en 2018, y cuando la UCJC se había desvinculado completamente de esta historia, Pérez Abellán siguió manteniendo la tesis del estrangulamiento de Prim esta vez en un libro que titulaba El vicio español del magnicidio. De Prim a Carrero, la clave oculta de los crímenes que marcaron nuestro destino. Lo editó también Planeta. La lectura de los cinco primeros renglones del primer capítulo nos ahorra cualquier comentario sobre su contenido: “Este libro desmonta la versión oficial sobre las muertes de Prim, Cánovas, Canalejas, Dato y Carrero Blanco, y también la del regicidio frustrado de Alfonso XIII. Su fascinante tesis relaciona los sucesos entre sí y los desvincula del anarquismo, descubriéndolos como crímenes de Estado". Francisco Pérez Abellán, desgraciadamente, fallecería a finales de diciembre de 2018 a los 64 años. En las necrológicas que en la prensa se escribieron, se le recordó con razón, "como uno de los grandes referentes del periodismo español de sucesos" y como colaborador de programas de televisión de tanto éxito como "Esta noche cruzamos el Mississippi", "Crónicas marcianas" y "Cuarto Milenio" o del programa de radio "Es la mañana de Federico" junto a Federico Jiménez Losantos, menos o nada por lo que escribió sobre la Historia Contemporánea de España. Véase, por ejemplo, su obituario en El Mundo del 28 de diciembre de 2018. El Instituto que ya hemos citado de la doctora Robledo le ha dado el nombre de Francisco Pérez Abellán a la beca de formación profesional que concede a alumnos de países de habla hispana "en honor a un periodista e investigador de excelencia recientemente fallecido". 


\section{LA SOCIEDAD BICENTENARIO GENERAL PRIM 2014. UN DISCRETO BALANCE}

Frente a la polémica que rodeó desde el principio la comisión creada en el seno de la UCJC, esta Sociedad que parecía que era la que oficialmente iba a encargarse del programa de actos con los que se pretendía conmemorar el bicentenario del nacimiento del general tuvo un recorrido más discreto y, finalmente, ni siquiera pudo organizar todos los actos que inicialmente tenía previsto $^{38}$. Y es que lo primero que llamó la atención de esta Sociedad fue su heterogénea composición. Presidida por Pau Roca y Blasco, entonces secretario de la Federación Española del Vino,-la patronal de las bodegas españolas- integraba, entre otros, a Luis Alejandre, general que había sido Jefe del Estado Mayor del Ejército y autor de un libro sobre la expedición mejicana de Prim, a Ramón Tamames, catedrático jubilado de Economía, al abogado y exministro José María Michavila, al "sociólogo y escritor" José María Fontana y como único historiador profesional a Emilio de Diego, que entones era profesor titular de Historia Contemporánea de la UCM y autor de una biografía de Prim, que ya hemos citado. Se trataba de una Sociedad privada y "sin ánimo de lucro", que contaba con el patrocinio de la Caixa y que también tendría el respaldo de instituciones como el Fomento del Trabajo Nacional -la patronal catalana- el Congreso de los Diputados, el Ejército, la Academia de la Historia y los Ayuntamientos de Madrid y Reus ${ }^{39}$.

En el ámbito de las publicaciones dos han sido los libros que ha dejado esta Sociedad como legado. El primero fue el de los “Discursos parlamentarios" de Prim editado por el Congreso de los Diputados dentro de su colección de "Biografías" sobre las principales figuras del parlamentarismo español. Se trata de una obra en la que Emilio de Diego hace una antología de los discursos pronunciados por el general y que está precedida por una serie de trabajos sectoriales de desigual factura y contenido ${ }^{40}$. De los siete, sólo dos tratan la cuestión del atentado y la muerte del general. El titulado "Prim: un apunte biográfico" firmado por Emilio de Diego, en el que este profesor de la UCM resume la misma tesis que había sostenido en su libro del 2003, que no era otra que la que habían elaborado Pedrol y Rueda y que culpaba a Paúl de ser uno de los autores materiales del crimen contando con la colaboración de

38 La página web que inicialmente tenía esta Sociedad -http://www.prim2014.com-, también ha desaparecido de la Red y del alojamiento que tenía en la de la entidad "Acción Cultural España", dependiente del Gobierno de España. Todavía podemos encontrar información sobre la Sociedad Bicentenario en la página que tiene una de las integrantes de la misma, la licenciada María José Rubio en la web titulada "Madrid, Villa y Corte". Vid. http://www.madridvillaycorte.es/mjrubio-prim. php (consulta realizada el 28-11-2020).

39 Sin embargo, el presidente de esta comisión se quejaría en una de las seis mesas redondas que organizó con la Fundación Independiente de la ignorancia con la que el Gobierno del Estado había tratado a esta comisión. Vid. VV.AA., El General Prim en su Bicentenario, 1814-2014, Madrid, Fundación Independiente, 2015, p. 106.

40 RUBIO, María José (coord). Juan Prim y Prats (1814-1870). Discursos parlamentarios, Madrid, Congreso de los Diputados, 2012. 


\section{DIEGO CARO CANCELA}

Pastor como inductor y Solís como instigador ${ }^{41}$. Más novedoso, por el contrario, era el planteamiento del otro trabajo, el que firmaba José María Fontana Bertrán y que se titulaba “El magnicidio de don Juan Prim y Prats".

Reusense como Prim, Fontana Bertrán ya había publicado un libro en el año 2011 en el que sostenía una versión sobre los autores del atentado, totalmente alejada de la que hasta entonces había difundido el libro de Pedrol, y que tanto se había conocido y copiado ${ }^{42}$.

La primera novedad de su libro era que negaba completamente cualquier participación de Paúl y Angulo en la preparación y la ejecución del atentado, mientras que mantenía las imputaciones de Pastor y Solís. Para ello, Fontana analiza las pruebas que había contra el político republicano. Por ejemplo, frente a los que decían que se había escuchado la voz de Paúl en la calle del Turco, contraponía la declaración de uno de los ayudantes del general, González Nandín, que también le acompañaba en la berlina y que resultó herido, y jerezano como Paúl, que en su declaración manifestó al juez que no era la suya; un testimonio que, por cierto, no cita Pedrol en su libro ${ }^{43}$. Y, sobre la lista que el director del periódico republicano moderado La Discusión había entregado a las autoridades el día antes del magnicidio con los nombres de los que iban a participar en el atentado, Paúl incluido, Fontana llama la atención de la rivalidad política y periodística que mantenía con este, y que la misma se la había hecho llegar el propio José María Pastor, el jefe de la escolta de Serrano $^{44}$. Y, por último, se pregunta: ¿entonces, por qué se escondió Paúl en los días previos y posteriores al atentado? Él mismo se responde: porque huyó de los veintidós suplicatorios que entre el 15 y el 25 de diciembre llegaron al Congreso de los Diputados pidiendo su procesamiento y el de otros integrantes de la redacción de su periódico El Combate por algunos de los artículos que publicaron ${ }^{45}$. Por tanto, la conclusión a la que llega José María Fontana no podía ser más rotunda:

41 Ibídem., p. 208.

42 FONTANA BERTRÁN, José María. El magnicidio del general Prim (los verdaderos asesinos), Astorga, Editorial Akrón, 2011. En la introducción de este libro, Fontana hacía una sincera y sorprendente declaración: "Yo no voy a ser una excepción y pruebas, lo que se dice pruebas no voy a aportar. Digamos que voy a aportar casualidades, tantas casualidades que el lector sacará su propia conclusión. Insisto, por lo que pueda pasar, no voy a acusar a nadie, voy a presentar opiniones avaladas por documentos y por la bibliografía publicada al respecto, el resto se lo dejo al lector y a los historiadores" (p. 17). Como se ha dicho, él se definía como "sociólogo y escritor".

43 Ibídem., pp. 204-205. Javier Rubio, en un libro que comentaremos a continuación afirma que González Nandín se refería en su declaración a otra persona. Vid. RUBIO, Javier. Juan Prim. Sus años de gobernantes. Su asesinato. Una revisión necesaria. Madrid, Ministerio de Asuntos Exteriores, 2017. Incluso en el apéndice documental reproduce la declaración de este ayudante, que tampoco deja claro lo que afirma Rubio a tenor de la forma en la que está redactada (pp. 745-746).

44 Ibídem., PP. 221-222.

45 FONTANA BERTRÁN, José María. El magnicidio del general Prim, en RUBIO, María José (coord.), op. cit., p. 266. 
"La endeblez de las pruebas aportadas contra Paúl $\gamma$ Angulo y el tufo que tienen a preparadas de antemano, me hacen concluir que Paúl $\gamma$ Angulo ni preparó ni participó en el magnicidio de Prim" ${ }^{46}$.

Tampoco aportan mucho las actas publicadas de las seis de mesas redondas que esta Sociedad Bicentenario organizó con una llamada Fundación Independiente a lo largo del último trimestre del año 2014 y editadas como libro con el título de El General Prim en su Bicentenario $1814-2014^{47}$. Del variopinto panel de los dieciocho ponentes que intervinieron en las seis mesas, sólo tres podrían considerarse historiadores que habían escrito y publicado sobre Prim y el tiempo histórico que le tocó vivir ${ }^{48}$. Por este motivo, la única aportación verdaderamente novedosa que tiene el libro es la ponencia que presentó el catedrático de Historia Contemporánea Borja de Riquer, titulada "El culto a Prim: entre manipulaciones y equívocos", en la que analiza el uso que del recuerdo de este militar catalán hicieron después de su muerte los distintos partidos presentes en la vida política de Barcelona ${ }^{49}$. Y es que Borja de Riquer, separándose del tono hagiográfico que tienen la mayoría de los textos que se incluyen es este libro, no duda en concluir que Prim fue un personaje en vida y muerto "tan admirado como censurado", con actitudes a veces poco éticas incluso con sus propios seguidores ${ }^{50}$.

Por último, y también al calor de este bicentenario, en este 2014 Emilio de Diego presentaba una nueva edición de la biografía de Prim que había publicado once años antes ${ }^{51}$. Ahora incorporaba más materiales y nuevos capítulos, aunque no añadía nada que fuera inédito sobre la cuestión del atentado, eso sí, en un apartado de este nuevo libro no dudaba en responder a los ataques que desde meses antes le venía dirigiendo el periodista Francisco Pérez Abellán, con un titular que lo decía todo: “La conjuración de los necios (con algún listo). Se acabón ${ }^{52}$.

\section{Ibídem., p. 270.}

47 Una primera edición del libro fue publicada en Madrid a finales del 2014 por esta fundación y hubo una segunda edición ampliada al año siguiente, que es la que hemos consultado.

48 Eran Emilio de Diego, Borja de Riquer y José Luis Ollero

49 VV.AA., El General Prim..., La ponencia de Borja de Riquer en las páginas 84-92.

50 Ibídem., P. 92.

51 DIEGO GARCíA, Emilio de. Prim. Mucho más que una espada, Madrid, Editorial Actas, 2014.

52 Ibídem., pp. 431-434. Aquí contaba, por ejemplo, que, "cuando este atleta del disparate -se refiere a Pérez Abellánemprendió su particular batalla, no por la verdad histórica, sino por el espectáculo morboso con fines mercantiles, pedí a los miembros de la Sociedad para la Conmemoración del Bicentenario del general Prim y a otras muchas personas, entre ellos colegas historiadores y los herederos de los títulos de la familia Prim, entre otros, no entrar en polémicas con semejante individuo" (p. 433). 


\section{DIEGO CARO CANCELA}

\section{MÁS SOBRE EL ASESINATO}

Pasada la fecha de la conmemoración, en el año 2017 el diplomático jubilado Javier Rubio publicaba una última biografía de Prim, en la que dedicaba una parte importante de la misma al análisis de la historiografía hasta entones conocida sobre el atentado ${ }^{53}$. Rubio, reiteraba en líneas generales la tesis que ya había sostenido en su obra anterior, España $\gamma$ la guerra de 1870, mostrándose especialmente crítico con los libros de Rueda Vicente y Fontana Bertrán. Al primero le censuraba que hubiera hecho una lectura poco atenta y ligera del contenido del sumario y que incluso le hubiera plagiado algunas páginas de su libro anterior, y descalificaba su investigación porque en su opinión lo que había escrito carecía de "la mínima fiabilidad" ${ }^{54}$. Y, al segundo, que se hubiera dedicado a sostener la exculpación de Paúl, en contra de lo que él defendía, y que tuviera un conocimiento incompleto de la obra de Pedrol y de la sociedad española de la época, de aquí que llegara a calificarlo de "historiador diletante" ${ }^{55}$.

Como Pedrol, Javier Rubio no tenía ninguna duda acerca de la participación de Paúl en el magnicidio, motivo por el cual, según escribía, le incomodaba que el diputado republicano por Jerez pareciera “hoy intocable en esta segunda Restauración (sic)" ${ }^{56}$. También descalificaba el libro de Pérez Abellán, Matar a Prim, porque mostraba "su total invalidez tanto desde el punto de vista científico-forense como del histórico" y no dudaba en definir como "disparatada" la tesis que en él se sostenía del estrangulamiento de Prim ${ }^{57}$. Finalmente, este diplomático analizaba los hitos procesales que consideraba más relevantes de la larga instrucción del sumario y dedicaba todo el capítulo IX del libro a defender su tesis central sobre el atentado. Sin más pruebas que las ya conocidas y refutadas por Fontana, completadas con las opiniones oídas por terceros de algunos republicanos más moderados muy críticos con las acciones y actitudes de Paúl, no dudaba en calificar a éste como "diputado, agitador político y magnicida" ${ }^{58}$. Le daba también pábulo a una fantasmal insurrección republicana que debía coincidir con el momento del atentado, pero de la que la prensa de esta ideología -especialmente El Combate y La Discusión- no habían comentado nada en los días anterio-

53 RUBIO, Javier. Juan Prim. Sus años de gobernantes. Su asesinato. Una revisión necesaria. Madrid, Ministerio de Asuntos Exteriores, 2017. La cuestión del atentado y la muerte del general Prim ocupaba toda la segunda parte del libro, pp. $441-704$.

54 Ibídem., p. 545.

55 Ibídem., pp. 556-558.

56 Ibídem., p. 568.

57 Ibídem., pp. 570-575.

58 Ibídem., p. 630. 
res y consideraba relevante en esta tesis de la culpabilidad lo que sucedió años después -en 1885- cuando se reabrió la causa contra Paúl en el momento en que se le localizó estableciendo su residencia en Francia.

Todo el celo que Rubio pone en inculpar a Paúl se convierte en prevenciones cuando se dedica a narrar lo que llama la "supuesta implicación" del Regente, esto es, del general Serrano. Según lo que escribe, el que José María Pastor , al que califica como "jefe de su ronda secreta", estuviera imputado por los jueces en el atentado como ya se ha señalado, no tenía por qué llevar necesariamente a sospechar del general unionista y conocido rival político de Prim ${ }^{59}$.

Caso bien distinto era el del duque de Montpensier y ésta era la novedad de la tesis de Rubio, acentuando lo que ya había escrito anteriormente en su libro de 1989. Ahora éste era presentado abiertamente como "el gran instigador, encubridor y financiador del magnicidio" 60 . Destacaba su "gran ambición" y, de una manera un tanto embrollada, sostenía sin ninguna prueba que el atentado de Prim debía ser la señal para dar "un golpe de estado que tenía como objetivo poner al duque (...) en el trono de España". Y no sólo esto, además, no dudaba en escribir que esa fantasmal insurrección republicana que debía estallar a continuación, y de la que nadie sabía nada, estaba "estimulada por los propios orleanistas", todo lo cual parecía un poco disparatado $^{61}$.

\section{CONCLUSIONES}

Pasado el bicentenario y leída toda la literatura histórica publicada al calor del mismo no creemos que se haya avanzado mucho en el conocimiento de la vida y la muerte del general Prim. Y lo afirmamos así porque en los distintos trabajos que se han ido publicando se han cometido los mismos errores que en su día tuvo el propio Pedrol Rius en su libro. El primer error ha sido que se le ha dado la consideración de "verdad histórica" a algunos de los testimonios o declaraciones contenidas en el sumario que se instruyó con motivo del asesinato, pese a las numerosas irregularidades que se produjeron durante su tramitación, con testimonios interesados, declaraciones que luego se cambiaban, documentos manipulados y jueces que iban y venía desde que se abrió, en la misma noche del 27 de diciembre de 1870, hasta su primer cierre sin juicio en 1878 y el definitivo en 1892. Baste señalar un detalle

59 A rechazar lo que Fontana y Pérez Abellán han escrito sobre esta implicación dedica las páginas 672-675.

60 Ibídem., p. 682.

61 Ibídem., p. 694. Sin embargo, en la nota 102 que va al pie de esta página da a entender lo contrario cuando escribe que, "en ningún caso Montpensier controlaba a los dirigentes republicanos". 


\section{DIEGO CARO CANCELA}

que cuenta Pérez Abellán en uno de sus libros: el testigo y también inculpado Juan José Rodríguez López, un "manipulador sin escrúpulos" en palabras del periodista, llegó a prestar hasta cuarenta y cuatro declaraciones a lo largo de estos años ${ }^{62}$.

Por otra parte, hay que recordar lo que contiene un sumario o instrucción. Se trata de una etapa penal anterior al juicio durante la cual se realiza la investigación judicial del presunto delito y sobre las personas que se consideran culpables de haberlo cometido. Por tanto, lo que se hace es reunir pruebas suficientes -testigos, actos periciales, documentos o reconstrucciones- para imputar a la persona o personas potencialmente responsables, para que una vez que termine esta fase de investigación la causa pase a la etapa de juicio penal. Por tanto, el sumario no contiene, ni establece ninguna "verdad jurídica" y más en este del que hablamos que nunca terminó en un juicio. Por este motivo, considerar como verdaderas, imputaciones que se hicieron a lo largo de la instrucción por intereses personales o espurios es un error en el que no debe caer una investigación histórica mínimamente solvente. Da la impresión, cuando se leen algunos de estos libros o artículos publicados sobre el atentado de Prim, que lo que se quiso hacer ante todo fue buscar un culpable que le viniera bien a todos los que estaban situados en la gobernación del Estado y en las élites del Poder y esconder así otras responsabilidades o negligencias.

Por último, queremos señalar que lo que ha ocurrido con toda la historiografía dedicada al análisis del atentado de Prim es que se ha volcado en analizar un sumario en el que ya se han agotado las pruebas. Por el contrario, apenas se han explorado otras fuentes hemerográficas, documentales o memorialísticas que podrían aportar más luces o derribar algunos mitos históricos construidos sobre una increíble alianza republicana radical-unionista-montpensierista, personificada en la entente Paúl-Serrano-Montpensier, que carece de la más mínima credibilidad a la luz de otros documentos de la época. Mientras tanto, algunos y algunas vieron la posibilidad de hacer caja con esta historia y bien que lo intentaron. 